\title{
Why and where Wikipedia is cited in journal articles?
}

\author{
Fariba Tohidinasab*, Hamid R. Jamali \\ Department of Library and Information Studies, Kharazmi University, Tehran, Iran
}

\begin{abstract}
The aim of this research was to identify the motivations for citation to Wikipedia in scientific papers. Also, the number of citation to Wikipedia, location of citation, type of citing papers, subject of citing and cited articles were determined and compared in different subject fields. From all English articles indexed in Scopus in 2007 and 2012 that have cited Wikipedia, 602 articles were selected using stratified random sampling. Content analysis and bibliometric methods were used to carry out the research. Results showed that there are 20 motivations for citing Wikipedia and the most frequent of them are providing general information and definition, facts and figures. Citations to Wikipedia often were in the introduction and introductory sections of papers. Computer sciences, internet and chemistry were the most cited subjects. The use of Wikipedia in articles is increasing both in terms of quantity and diversity. However, there are disciplinary differences both in the amount and the nature of use of Wikipedia.
\end{abstract}

Keywords: Citation, citation analysis, citation motivations, content analysis, reasons of citation, Wikipedia

\section{INTRODUCTION}

Wikipedia, a free online encyclopedia that anyone can edit, includes close to 4 million entries and is now a much-used resource. ${ }^{[1]}$ The popularity of Wikipedia in the academic community has been growing since its creation in $2001^{[2]}$ and it will probably become increasingly important as a tool to send the scientific researches out. ${ }^{[3]}$ Despite its popularity, Wikipedia is not uniformly accepted as a credible and trustworthy resource for research. Obviously, the concern regarding Wikipedia's credibility stems from the unique process of content generation that allows essentially anonymous individuals to create and update articles. ${ }^{[4]}$ However, with the continuous development and growing readership, concerns about the credibility of this source still exist.

*Address for correspondence:

E-mail: tn_fariba@yahoo.com

\begin{tabular}{|l|l|}
\hline \multicolumn{2}{|c|}{ Access this article online } \\
\hline Quick Response Code: & \\
\hline & \\
\hline
\end{tabular}

Despite the uncertainties about the credibility and quality of Wikipedia, Wikipedia is increasingly being cited by researchers. ${ }^{[5,6]}$ Although, there have been many studies about Wikipedia, we still do not know why researchers cite Wikipedia. Our aim in this study is to answer this question. More specifically we seek answers to the following questions:

- What are the motivations for citing Wikipedia?

- Where in journal articles (in which parts) Wikipedia is cited?

- How is the distribution of citations to Wikipedia across different article types?

- What are the subjects of cited Wikipedia entries?

- How is the distribution of the citing articles across different subject categories?

\section{Literature Review}

We present the review of the past works in two sections. First we review studies about citation motivations and typing and then, studies related to Wikipedia.

\section{Citation Motivation Studies}

One of the first categorizations of citation types is the one by Garfield. ${ }^{[7]}$ He listed 15 reasons or motivations for citations, from paying homage to pioneers and giving 
credit for related work to disclaiming ideas of others and disputing priority claims of others (negative homage). ${ }^{[7]}$

Since Garfield's list, several other researchers proposed categorizations of citation types or motivations. Table 1 shows the list of these authors with the approach they used to generate their list and the number of citation types they proposed in their categorization. Empirical means that the categorization does not have a philosophical or theoretical basis.

As we can see from Table 1, there are several categorizations of citation types or motivations. They have been developed using different approaches and for different purposes. We summarize them in Table 2 which can be helpful for converging different lists in order to obtain a more exhaustive categorization. Discussing all of the categorizations presented in Table 1 is out of the scope of this paper and it would make this article too long. Another reason for avoiding such as a discussion is that after inspecting all of them, we realized that none of them were suitable for our purpose. Wikipedia is an encyclopedia with anonymous articles and no one would cite an anonymous article that could be edited at any time for reasons such as negational or persuasive or some other motivations.

\section{Studies on Wikipedia}

A few studies have investigated the attention that Wikipedia attracted in academe. Park ${ }^{[5]}$ showed the increasing number of research publications about Wikipedia and citations made to it since its launch in 2001 and scholars in the fields of computer science, information science and social sciences are the most active in citing Wikipedia. Huggett ${ }^{[6]}$ replicated Park's study by looking for "Wikipedia" in titles, keywords or abstracts of scholarly papers published in journals indexed in Scopus and found a dramatic increase in the number of publications referring to Wikipedia as a source. She also compared the number of scholarly papers with "Wikipedia" in their references and the number of scholarly papers with other free online encyclopedias in their references. Results showed that although the use of other free online encyclopedias increased annually, the increase in the use of Wikipedia as a source was greater.

A number of other studied have focused on how and why Wikipedia is used. Baker's ${ }^{[2]]}$ study on citations to Wikipedia in law reviews showed that one of the most common justifications for citing Wikipedia by writers
Table 1: List of classifications of citation motivations

\begin{tabular}{|c|c|c|}
\hline Name & Procedure & No. of items \\
\hline Garfield $^{[7]}$ & Empirical & 15 \\
\hline $\begin{array}{l}\text { Moravcsik and } \\
\text { Murugesan }{ }^{[8]}\end{array}$ & $\begin{array}{l}\text { Empirical (context analyses of } \\
\text { citations in citing documents) }\end{array}$ & 4 \\
\hline Oppenheim and Renn ${ }^{[9]}$ & Empirical (content analysis) & 7 \\
\hline Chubin and Moitra ${ }^{[10]}$ & $\begin{array}{l}\text { Empirical (context analyses of } \\
\text { citations in citing documents) }\end{array}$ & 6 \\
\hline Spiegel-Rosing ${ }^{[11]}$ & $\begin{array}{l}\text { Empirical (context analyses of } \\
\text { citations in citing documents) }\end{array}$ & 13 \\
\hline Frost $^{[12]}$ & $\begin{array}{l}\text { Empirical (context analyses of } \\
\text { citations in citing documents) }\end{array}$ & 5 \\
\hline Duncan et al. ${ }^{[13]}$ & Unknown & 26 \\
\hline Peritz ${ }^{[14]}$ & Unknown & 8 \\
\hline Brooks $(1985)^{[15]}$ & $\begin{array}{l}\text { Empirical (citer motivation } \\
\text { surveys or interviews) }\end{array}$ & 7 \\
\hline Vinkler ${ }^{[16]}$ & $\begin{array}{l}\text { Empirical (citer motivation } \\
\text { surveys or interviews) }\end{array}$ & 2 \\
\hline Cano ${ }^{[17]}$ & $\begin{array}{l}\text { Empirical (citer motivation } \\
\text { surveys or interviews) }\end{array}$ & 8 \\
\hline Bonzi and Snyder ${ }^{[18]}$ & Empirical (content analysis) & 12 \\
\hline Dimitroff and Arlitsch ${ }^{[19]}$ & Unknown & 3 \\
\hline Shadish et al. ${ }^{[20]}$ & $\begin{array}{l}\text { Empirical (citer motivation } \\
\text { surveys or interviews) }\end{array}$ & 6 \\
\hline White and Wang ${ }^{[21]}$ & Unknown & 25 \\
\hline Case and Higgins ${ }^{[22]}$ & Empirical (content analysis) & 6 \\
\hline Krampen et al. ${ }^{[23]}$ & $\begin{array}{l}\text { Empirical (context analyses of } \\
\text { citations in citing documents) }\end{array}$ & 11 \\
\hline Campanario ${ }^{[24]}$ & Unknown & 4 \\
\hline $\begin{array}{l}\text { Bornmann and } \\
\text { Daniel }(2008)^{[25]}\end{array}$ & Unknown & 8 \\
\hline Teufel et al. ${ }^{[26]}$ & Empirical (content analysis) & 4 \\
\hline Harwood $^{[27]}$ & $\begin{array}{l}\text { Combinational (quantitative } \\
\text { and qualitative) }\end{array}$ & 11 \\
\hline Peroni and Shotton ${ }^{[28]}$ & Unknown & 4 \\
\hline
\end{tabular}

and judges was that Wikipedia is comparable with other sources and therefore is a reliable source. A common reason for citing Wikipedia was to give definitions of new terms. In a similar research Head and Eisenberg ${ }^{[30]}$ examined why and how students use Wikipedia during the course-related research process. They showed Wikipedia was used commonly at the beginning of the research process. Students used it for a range of reasons including to give a summary about a topic, to define terms, and to obtain introductory information about a new topic. Students who were majoring in architecture, engineering, or sciences were more likely to use Wikipedia than students in other majors.

Another group of studies have dealt with the credibility and quality of Wikipedia. West and Williamson ${ }^{[31]}$ examined quality of 106 articles in Wikipedia in order to assess whether Wikipedia can be used and recommended as a credible reference or information tool. The findings indicated that overall the articles were objective, clearly 
Table 2: Citation motivations based on literature

\begin{tabular}{|c|c|}
\hline $\begin{array}{l}\text { General citation } \\
\text { motivation }\end{array}$ & Specific reasons for citation \\
\hline \multirow[t]{8}{*}{ Affirmational } & $\begin{array}{l}\text { Justifying the topic of research and representing } \\
\text { gaps and limitations of past research }\end{array}$ \\
\hline & Justifying the method and methodology employed \\
\hline & Justifying claims \\
\hline & Citing works to confirm owns work \\
\hline & Extending previous publications \\
\hline & Updating cited work \\
\hline & Agreeing with ideas or findings of cited work \\
\hline & Using cited work as the basis for the citing work \\
\hline \multirow[t]{8}{*}{ Negational } & Negative evaluating of cited work \\
\hline & Disagreeing with cited work \\
\hline & Qualifying cited work \\
\hline & Refusing cited work \\
\hline & Critiquing cited work \\
\hline & Correcting cited work \\
\hline & Disproving cited work \\
\hline & Questioning the data or whole of cited work \\
\hline \multirow[t]{3}{*}{ Historical } & Tracing the history or background of a subject \\
\hline & Acknowledging the work of pioneers \\
\hline & $\begin{array}{l}\text { Citing past studies as similar works on the } \\
\text { subject (mainly in the literature review section) }\end{array}$ \\
\hline \multirow{4}{*}{$\begin{array}{l}\text { Argumentative, } \\
\text { speculative, } \\
\text { hypothetical }\end{array}$} & $\begin{array}{l}\text { Citing works in relation to support or formulation } \\
\text { of research hypotheses }\end{array}$ \\
\hline & $\begin{array}{l}\text { Citing to support new hypotheses or guesses } \\
\text { researcher makes based on his/her findings }\end{array}$ \\
\hline & Citing to justify the significance of the research \\
\hline & $\begin{array}{l}\text { Citing to support new solutions, new methods or } \\
\text { suggestions for further works }\end{array}$ \\
\hline Conceptual & $\begin{array}{l}\text { Use of definitions, concepts, or theories of cited } \\
\text { work }\end{array}$ \\
\hline \multirow[t]{3}{*}{ Comparative } & Citing to compare the cited with the citing work \\
\hline & Citing to compare others' works \\
\hline & $\begin{array}{l}\text { Citing to suggest the citing work as an alternative } \\
\text { to cited work }\end{array}$ \\
\hline Methodological & $\begin{array}{l}\text { Citing in relation to methodology, methods or } \\
\text { analysis }\end{array}$ \\
\hline Casual & $\begin{array}{l}\text { Citing with no clear reason, explanation or } \\
\text { comment, making a perfunctory reference to cited } \\
\text { work }\end{array}$ \\
\hline Persuasive & $\begin{array}{l}\text { Citing works authored by recognized authority in } \\
\text { the field }\end{array}$ \\
\hline
\end{tabular}

presented, reasonably accurate and complete, although some were poorly written, contained unsubstantiated information, and provided shallow coverage of a topic.

Several other studies investigated issues such as motivations for contributing in Wikipedia (e.g. ${ }^{[32]}$ ), collaborating in Wikipedia (e.g. $\left.{ }^{[33]}\right)$, quality of its content (e.g. ${ }^{[34]}$ ) and other issues that are out of the scope of our study.

Overall, few studies investigated the nature of citations made to Wikipedia in journal articles in terms of motivations, subjects, article type, and location of citation. We intend to clarify these issues in this research.

\section{SUBJECTS AND METHODS}

The list of indexed English articles in Scopus published in 2007 and 2012 that have cited Wikipedia were retrieved. We selected these 2 years to compare the findings within a 5 -year interval. We used the reference field of Scopus database to search for those articles citing Wikipedia.org. The search was restricted to Journal for "Type of Resource" and to Article for "Document Type." Then we used stratified random sampling (subject categories as strata) method to draw a sample (with 95\% confidence level) of 256 (out of 1006) articles for 2007 and 346 (out of 4835) articles for 2012.

Bibliometric and content analysis methods were used to carry out this research. Bibliometric methods were used to explore the number of citations to Wikipedia and also to examine the other quantitative aspects. Content analysis was used to investigate the citation motivations and the type and the location of citations. The first author went through the full-text of each article and used a check-list to record the number of its citations to Wikipedia, citation motivations, the location of citation based on the article's subheadings, the type of citing article, and the subject of cited Wikipedia entry. The second author did the same for a few of the articles as an inter-coder consistency test and as a measure to achieve reliability and validity.

To determine the citation motivation we first started to use the categories suggested by past researchers [Table 2]. However, after a few articles it became clear that those categories were insufficient and unsuitable. This was because all of those classifications have been mainly developed with regard to citations to journal articles. As mentioned in the literature review, clearly, Wikipedia entries are different from journal articles in nature and people are unlikely to cite them for reasons such as the negational reasons. Therefore, we needed a new classification that took into account more precise reasons. Therefore, we used an inductive approach and as we went through the articles we gradually developed a classification of citation motivations. We did this for about 50 articles and then refined the classification and use the refined version for the analysis. To determine the subject of citing articles we used the subject categories of Scopus.

\section{RESULTS}

\section{Citation Motivations to Wikipedia}

We identified 20 motivations for citation to Wikipedia as below: 
- Facts and figures: Facts and numerical information are lobtained from Wikipedia or two things are compared using the information of Wikipedia. Sometimes, Wikipedia is used as a source of data analyzed in the research

- Explanation: Information from Wikipedia is used to explain something, make an argument or give reason for something (e.g. what is the reason for the color of gold)

- About Wikipedia: One of the articles of Wikipedia is discussed

- Definition: Wikipedia is used to give definition of a term or concept

- Graphs: Figure, graph, map, or tables are taken from Wikipedia

- Exemplar: Wikipedia is cited as an example (e.g. as an example of Web 20.0 technology)

- Methodological: Wikipedia information is used to introduce or describe the method of research

- Further information: Readers are referred to Wikipedia as a source for further or more up-to-date information on the topic

- Chemical equation: Equations relevant to chemical materials is taken from Wikipedia

- Equation or formula: Mathematical equation, formula or theorem is used, described or explained using information from Wikipedia

- Non English Wikipedia: Readers are referred to Wikipedia in other languages to access information. This is normally used when the topic is a local topic and nonpresent or poorly presented in English Wikipedia

- Sampling: Wikipedia information is used as a sampling framework to do a sampling (e.g. using the list of silent films on Wikipedia to draw a sample)

- Quotation: A quotation is taken from Wikipedia

- Literature review: Wikipedia information is used to present a summary of past studies

- Casual: Wikipedia is mentioned and cited for no specific reason in a perfunctory way

- Biography: Wikipedia is used for biographical information

- Geography: Wikipedia is used for geographical information including countries' or regions' demographics or populations

- History: Wikipedia is used for historical information

- General information: Background or general information about a topic is presented using Wikipedia or something is mentioned as an example of something else using information from Wikipedia

- News: A new item is stated that its relevant information are in Wikipedia.

\section{Number of Citations to Wikipedia}

Table 3 shows the number of citations to Wikipedia in articles in 2007 and 2012 and the average of citation to Wikipedia per article. An article may contain more than one citation to Wikipedia. The average number of citation to Wikipedia is the highest in health sciences with 1.7 (2007) and 1.3 (2012).

\section{Type of Articles Citing Wikipedia}

Table 4 shows that most of the articles citing Wikipedia are research articles (63.7\% in 2007 and $80.3 \%$ in 2012). Review articles accounted for a-third of citing articles in 2007 and for almost a-fifth in 2012.

\section{Citation Motivation}

In general, we found 20 motivations or reasons for citing Wikipedia; but the numbers of motivations varied from 2007 to 2012 and from one subject to another. Table 5 shows these differences. The most frequent reason to cite Wikipedia was presenting general information. The fewest number of citations to Wikipedia (0.7) was made to acquire Chemical Equation.

\section{Location of Citation to Wikipedia in Articles}

Citation to Wikipedia appears in different parts of articles. Table 6 shows the location of citation to Wikipedia in articles in 2007 and 2012. We simply used the names of the sections of articles in which the citations appeared (except for "Body"). This is why there is a "results and discussion"

Table 3: Number of citations to Wikipedia in 2007 and 2012 articles

\begin{tabular}{lccccccc}
\hline Subject area & \multicolumn{2}{c}{$\begin{array}{c}\text { No. of } \\
\text { articles }\end{array}$} & \multicolumn{2}{c}{$\begin{array}{c}\text { No. of } \\
\text { citations }\end{array}$} & \multicolumn{2}{c}{$\begin{array}{c}\text { Citations } \\
\text { per article }\end{array}$} \\
\hline Publication year & 2007 & 2012 & 2007 & 2012 & 2007 & 2012 \\
Biological sciences & 38 & 40 & 52 & 52 & 1.4 & 1.3 \\
$\begin{array}{l}\text { Humanities and } \\
\text { social sciences }\end{array}$ & 64 & 66 & 94 & 82 & 1.2 & 1.5 \\
Physical sciences & 118 & 197 & 161 & 259 & 1.3 & 1.4 \\
Health sciences & 36 & 43 & 62 & 57 & 1.3 & 1.7 \\
Total & 256 & 346 & 369 & 450 & 1.3 & 1.4 \\
\hline
\end{tabular}

Table 4: Type of articles citing Wikipedia

\begin{tabular}{lccccc}
\hline Article type & \multicolumn{2}{c}{2007} & & \multicolumn{2}{c}{$\mathbf{2 0 1 2}$} \\
\cline { 2 - 3 } \cline { 5 - 6 } & $\mathbf{N}$ & \% & & N & \% \\
\hline Research article & 163 & 63.7 & & 278 & 80.3 \\
Review article & 85 & 33.2 & & 64 & 18.5 \\
Case study & 8 & 3.1 & 4 & 1.2 \\
Total & 256 & 100 & & 346 & 100 \\
\hline
\end{tabular}


Table 5: Comparison of citation motivations in different subject fields (\%)

\begin{tabular}{|c|c|c|c|c|c|c|c|c|}
\hline \multirow[t]{2}{*}{ Motivations } & \multicolumn{4}{|c|}{2007} & \multicolumn{4}{|c|}{2012} \\
\hline & $\begin{array}{l}\text { Humanities and } \\
\text { social sciences }\end{array}$ & $\begin{array}{l}\text { Health } \\
\text { sciences }\end{array}$ & $\begin{array}{l}\text { Biological } \\
\text { sciences }\end{array}$ & $\begin{array}{l}\text { Physical } \\
\text { sciences }\end{array}$ & $\begin{array}{l}\text { Humanities and } \\
\text { social sciences }\end{array}$ & $\begin{array}{l}\text { Health } \\
\text { sciences }\end{array}$ & $\begin{array}{l}\text { Biological } \\
\text { sciences }\end{array}$ & $\begin{array}{l}\text { Physical } \\
\text { sciences }\end{array}$ \\
\hline Facts and figures & 8.51 & 12.9 & 5.8 & 9.3 & 6.1 & 29.8 & 17.3 & 18.4 \\
\hline Explanation & - & - & 5.8 & 1.9 & - & 1.8 & 1.9 & 0.3 \\
\hline About Wikipedia & 2.1 & - & - & - & - & 1.8 & - & - \\
\hline Definition & 19.1 & 27.4 & 13.5 & 7.5 & 26.8 & 1.8 & 5.8 & 12.0 \\
\hline Graphs & 3.3 & 8.1 & 3.8 & 4.4 & 7.3 & 3.5 & 5.8 & 6.2 \\
\hline Exemplar & 2.1 & 1.6 & 1.9 & 1.9 & 1.2 & - & 1.9 & - \\
\hline Methodological & - & 1.6 & 1.9 & 2.5 & - & - & 3.8 & 1.5 \\
\hline Further information & 20.2 & 3.2 & 3.8 & 9.3 & 8.5 & - & - & 9.3 \\
\hline Chemical equation & - & - & - & - & - & - & - & 0.7 \\
\hline Equation or formula & - & - & - & 1.9 & 1.2 & - & - & 2.3 \\
\hline Non-English Wikipedia & 1.1 & - & - & 1.9 & - & - & - & - \\
\hline Sampling & 1.1 & - & - & - & - & - & - & - \\
\hline Quotation & 4.2 & - & - & - & - & - & - & - \\
\hline Literature review & 1.06 & 1.6 & - & - & - & - & - & - \\
\hline Casual & - & 1.6 & - & - & - & - & - & - \\
\hline Biography & - & - & - & 1.3 & 2.5 & - & 3.8 & - \\
\hline Geography & - & 3.2 & - & - & - & 5.3 & 5.8 & 1.9 \\
\hline History & - & 1.6 & 7.7 & 0.6 & 2.4 & 1.7 & - & 2.3 \\
\hline General information & 36.12 & 37.1 & 55.7 & 56.9 & 44 & 52.6 & 51.9 & 44.4 \\
\hline News & 1.06 & - & - & 0.6 & - & 1.7 & 1.9 & 0.7 \\
\hline
\end{tabular}

Table 6: Location of citation to Wikipedia in articles in 2007 and 2012 (\%)

\begin{tabular}{|c|c|c|c|c|c|c|c|c|}
\hline \multirow[t]{2}{*}{ Article section } & \multicolumn{2}{|c|}{$\begin{array}{l}\text { Humanities and } \\
\text { social sciences }\end{array}$} & \multicolumn{2}{|c|}{$\begin{array}{l}\text { Health } \\
\text { sciences }\end{array}$} & \multicolumn{2}{|c|}{$\begin{array}{l}\text { Biological } \\
\text { science }\end{array}$} & \multicolumn{2}{|c|}{$\begin{array}{l}\text { Physical } \\
\text { science }\end{array}$} \\
\hline & 2007 & 2012 & 2007 & 2012 & 2007 & 2012 & 2007 & 2012 \\
\hline Abstract & - & - & - & - & - & - & 0.6 & - \\
\hline $\begin{array}{l}\text { Introduction and problem } \\
\text { statement }\end{array}$ & 16.0 & 23.2 & 22.6 & 29.8 & 42.3 & 46.2 & 29.2 & 37.1 \\
\hline Body & 47.8 & 35.4 & 46.8 & 12.3 & 28.8 & 3.8 & 19.3 & 7.7 \\
\hline Literature review & 2.1 & 1.2 & - & - & - & 3.8 & 4.3 & 2.7 \\
\hline Hypothesis & 1.1 & 2.4 & - & - & - & - & - & - \\
\hline Theoretical foundation & 16.0 & 15.9 & 1.6 & 5.3 & 1.9 & 5.8 & 18.6 & 18.1 \\
\hline Material and method & 4.3 & 2.4 & 12.9 & 36.8 & 11.5 & 23.1 & 6.2 & 13.5 \\
\hline Findings & 2.1 & - & 1.6 & 1.8 & 9.6 & 7.7 & 3.1 & 3.9 \\
\hline Analysis, and experiment & 1.1 & 2.4 & 3.2 & - & - & - & 3.1 & 2.7 \\
\hline Results and discussion & - & - & 1.6 & 1.8 & - & 5.8 & 8.7 & 9.3 \\
\hline Discussion & - & - & 8.1 & 12.3 & 5.8 & 3.8 & 4.3 & 1.9 \\
\hline Conclusion & 2.1 & - & - & - & - & - & 1.2 & 0.4 \\
\hline Footnotes and notes & 7.4 & 17.1 & 1.6 & - & - & - & 0.6 & 2.3 \\
\hline Appendices & - & - & - & - & - & - & 0.6 & 0.4 \\
\hline
\end{tabular}

and also a "discussion" section because some papers had a single "results and discussion" section and some others had a section for the results and another separate section for the discussion. Body was used for the main section of review articles and some case studies where authors do not use conventional headings such as findings or results. In review articles, body normally consists of topical sections of the article where authors present the review of the past works in a thematic way. The largest number of citations to Wikipedia in 2007 occurs in the main body of articles. Humanities and Social sciences with $47.8 \%$ had the highest rate of citations in the main body and the lowest number belongs to physical sciences with $19.3 \%$. The larger number of citation in this section in 2007 is probably because of the larger number of review articles (and case studies) citing Wikipedia in this year. In 2012, however, the largest per cent of citations appeared in the introduction and Biological Sciences with 46.2\% 
has the highest number of citation to Wikipedia in the introduction.

\section{Subjects of Citing Articles to Wikipedia}

Table 7 shows the subjects of articles citing Wikipedia. Of 27 fields, Social Sciences with 193 articles are the most citing subject field in 2007 and then there are Computer Science (120) and Medicine (113). In 2012, the most citing subject fields are Computer Science with 750 articles, Engineering (604) and Social Sciences (590) respectively.

\section{Subject of Cited Wikipedia Entries}

Figure 1 shows the subjects of cited Wikipedia entries in 2007 and 2012. In 2007, 18.2\% of cited Wikipedia entries belonged to subjects related to Computer Science, $10.0 \%$ belonged to chemistry and $9.2 \%$ belonged to the Internet. In 2012, entries related to the Internet (12.7\%), Chemistry (11.1\%) and Computer Science (10.0\%) accounted for the largest cited subjects.

\section{DISCUSSION}

Our aim was to find out why and where Wikipedia is used as an information source despite some doubts about its credibility. Motivations for citing Wikipedia can be categorized into 20 categories. Our findings lend support to the findings by Baker ${ }^{[29]}$ and Stoddard ${ }^{[35]}$ as both of them showed that one major use of Wikipedia is to provide a definition for a term or concept. Studies by both of them were in the field of law and in Stoddard's study more than half of the citations were to give a definition. Stoddard maintained that Wikipedia's entries

Table 7: Subjects of articles citing Wikipedia in 2007 and 2012

\begin{tabular}{|c|c|c|c|c|}
\hline \multirow[t]{2}{*}{ Subjects } & \multicolumn{2}{|c|}{2007} & \multicolumn{2}{|c|}{2012} \\
\hline & No. & $\%$ & No. & $\%$ \\
\hline Computer sciences & 120 & 10.4 & 750 & 13.8 \\
\hline Engineering & 101 & 8.7 & 604 & 11.1 \\
\hline Social science & 193 & 16.7 & 590 & 10.9 \\
\hline Mathematics & 51 & 4.4 & 289 & 5.3 \\
\hline Biochemistry, genetics and molecular biology & 69 & 6.0 & 197 & 3.6 \\
\hline Medicine & 113 & 9.8 & 531 & 9.8 \\
\hline Physics and astronomy & 66 & 5.7 & 342 & 6.3 \\
\hline Business, management, accounting & 32 & 2.8 & 122 & 2.2 \\
\hline Chemistry & 74 & 6.4 & 274 & 5.0 \\
\hline Decision sciences & 8 & 0.7 & 57 & 1.0 \\
\hline Materials science & 36 & 3.1 & 255 & 4.7 \\
\hline Art and humanities & 45 & 3.9 & 200 & 3.7 \\
\hline Agricultural and biological science & 50 & 4.3 & 165 & 3.0 \\
\hline Environmental science & 40 & 3.5 & 177 & 3.3 \\
\hline Earth and planetary science & 13 & 1.1 & 104 & 1.9 \\
\hline Energy & 6 & 0.5 & 114 & 2.1 \\
\hline Chemical engineering & 19 & 1.6 & 115 & 2.1 \\
\hline Nursing & 22 & 1.9 & 66 & 1.2 \\
\hline Health professions & 20 & 1.7 & 56 & 1.0 \\
\hline Pharmacology, toxicology, pharmaceutics & 18 & 1.6 & 149 & 2.7 \\
\hline Psychology & 16 & 1.4 & 66 & 1.2 \\
\hline Immunology and microbiology & 8 & 0.7 & 36 & 0.7 \\
\hline Multidisciplinary & 11 & 1.0 & 67 & 1.2 \\
\hline Economics, econometrics and finance & 11 & 1.0 & 55 & 1.0 \\
\hline Neuroscience & 3 & 0.3 & 22 & 0.4 \\
\hline Veterinary & 4 & 0.3 & 13 & 0.2 \\
\hline Dentistry & 6 & 0.5 & 15 & 0.3 \\
\hline Total & 1155 & 100 & 5431 & 100 \\
\hline
\end{tabular}

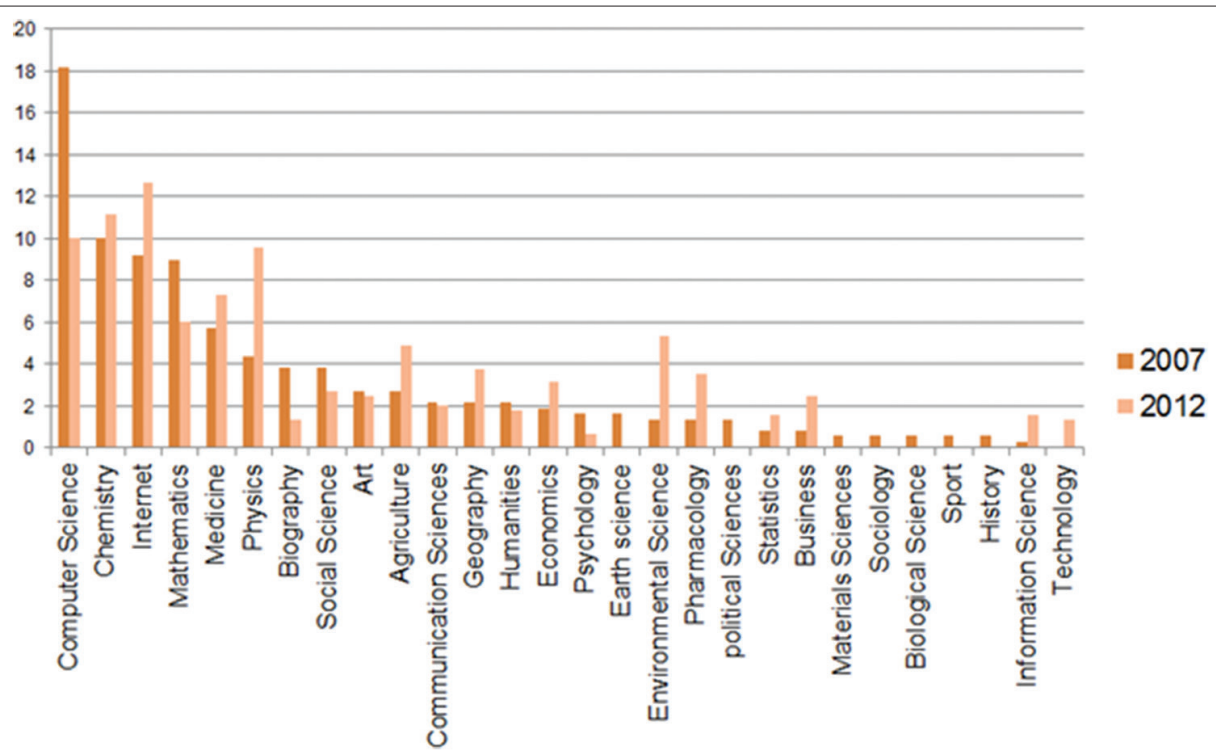

Figure 1: Subjects of cited Wikipedia entries in 2007 and $2012(\%)$ 
related to medicine, technology, and entertainment were the most used entries. Technology (e.g. computer, internet and so on) also appeared a popular subject in our study. The popularity of entries related to computer and the internet might be because there are more and better related entries in these areas in Wikipedia. This is something that needs further investigations. However, the academic community should be encouraged to improve the content of Wikipedia in all fields. Our study also showed that the rate of citing Wikipedia has increased, something that other studies (e.g., ${ }^{[5,6,35]}$ ) also found out.

Regarding the location of citations to Wikipedia, a considerable number of them appear in the introduction or introductory sections of articles. Some other citations appear in the sections such as materials and methods, theoretical foundation, and discussion. The fact that the introductory sections of articles host many citations to Wikipedia is not surprising as authors usually need to define and explain concepts in these parts, a need that Wikipedia can meet well.

Most of the citations to Wikipedia are citations to entries where there is certainty about their content and they have public acceptance like chemical equations or geographic or demographic information about a place and also physics or mathematical laws. Easy and quick access to Wikipedia facilitates citing Wikipedia in these cases.

The fact that the rate of citations in some fields such as computer sciences and chemistry is higher than subjects such as neurosciences might be because there are more entries in former subjects than in the latter, or maybe the quality of Wikipedia articles in subjects such as computer sciences and chemistry is better than that of subjects such as neurosciences. Another possible reason is that some subjects such as life sciences (e.g. neuroscience) are more sensitive and authors in these fields prefer to use a more trustworthy information resource than Wikipedia, where there is no well-established quality control mechanism such as peer review in place. All these explanations need further investigation.

Overall, Wikipedia is increasingly cited in the scholarly journal articles. Free and easy access to its content and that its content is updated quickly makes it attractive for users. The fact that the content is in a way the result of crowds' wisdom and is probably understandable for readers with different levels of knowledge might make it even more attractive and it has become a good start point to acquire general information about any subject. As a result, we can see more use of it in the introductory sections of the articles and for reasons such as providing a definition or giving background information. However, the diversity of citation motivations shows the extent to which Wikipedia can be used in scientific publications. We expect an increase in the quantity and diversity of the use of Wikipedia in science in the future. Our study shed some lights on the reasons of using Wikipedia and the way it is used; however, more studies are needed to investigate some of the issues we mentioned above.

\section{REFERENCES}

1. Giles J. Internet encyclopaedias go head to head. Nature 2005;438:900-1.

2. Lim S. How and why do college students use wikipedia. J Am Soc Inf Sci Technol 2009;60:2189-202.

3. Nielsen FA. Scientific citation in wikipedia. First Monday 2007;12. Available from: http://www.dx.doi.org/10.5210\%2Ffm. v12i8.1997. [Last accessed on 2013 Jan 05].

4. Miller J, Murray HB. Wikipedia in court: When and how citing Wikipedia and other consensus websites is appropriate. St Johns Law Rev 2010;84:1-24. Available from: http://www.ssrn.com/ abstract=1502759. [Last accessed on 2012 Aug 01].

5. Park T. The visibility of wikipedia in scholarly publications. First Monday 2011;16. Available from: http://www.dx.doi. org/10.5210\%2Ffm.v16i8.3492. [Last accessed on 2014 Jan 05].

6. Huggett $\mathrm{S}$. The influence of free encyclopedias on science. Res Trends 2012;27:7-10. Available from: http://www.researchtrensd. com/wpcontent/uploads/2012/03/research_trends_Issue27.pdf. [Last accessed on 2012 May 20].

7. Garfield E. Can citation indexing be automated? Essays Inf Sci 1962;1:84-90.

8. Moravcsik MJ, Murugesan P. Some results on the function and quality of citations. Soc Stud Sci 1975;5:86-92.

9. Oppenheim C, Renn SP. Highly cited old papers and reasons why they continue to be cited. J Am Soc Inf Sci 1978;29:225-31.

10. Chubin DE, Moitra SD. Content analysis of references: Adjunct or alternative to citation counting? Soc Stud Sci 1975;5:423-41.

11. Spiegel-Rosing I. Science studies - bibliometric and content-analysis. Soc Stud Sci 1977;7:97-113.

12. Frost CO. Use of citations in literary research - preliminary classification of citation functions. Libr Q 1979;49:399-414.

13. Duncan E, Anderson FD. McAleese R. Qualified citation indexing: Its relevance to educational technology. In: Duncan E, McAleese R, editors. Information Retrieval in Educational Technology. Proceedings of the First Symposium on Information Retrieval in Educational Technology, April 1, 1981, Aberdeen. Aberdeen, Scotland: University of Aberdeen; 1981. p. 70-9.

14. Peritz BC. A classification of citation roles for the social sciences and related fields. Scientometrics 1983;5:303-12.

15. Brooks TA. Private acts and public objects - An investigation of citer motivations. J Am Soc Inf Sci 1985;36:223-9.

16. Vinkler P. A quasi-quantitative citation model. Scientometrics 1987; 12:47-72.

17. Cano V. Citation behavior: Classification, utility, and location. J Am Soc Inf Sci 1989;40:284-90.

18. Bonzi S, Snyder HW. Motivations for citation - A comparison of self citation and citation to others. Scientometrics 1991;21:245-54.

19. Dimitroff A, Arlitsch K. Self-citations in the library and information science literature. J Doc 1995;51:44-56. 
20. Shadish WR, Tolliver D, Gray M, Sengupta SK. Author judgments about works they cite- three studies from psychology journals. Soc Stud Sci 1995;25:477-98.

21. White MD, Wang PL. A qualitative study of citing behavior: Contributions, criteria, and metalevel documentation concerns. Libr Q 1997;67:122-54.

22. Case DO, Higgins GM. How can we investigate citation behavior? A study of reasons for citing literature in communication. JAm Soc Inf Sci 2000;51:635-45.

23. Krampen $G$, Burkard $P$, Montada L. Wissenschaftsforschung in der Psychologie. Göttingen: Hogrefe, Verlag für Psychologie; 2002.

24. Campanario JM. Citation analysis. In: Feather J, Sturges P, editors. International Encyclopedia of Information and Library Science. London, New York: Routledge; 2003. p. 76-8.

25. Bornmann L, Daniel HD. What do citation counts measure? A review of studies on citing behavior. J Doc 2008;64:45-80.

26. Teufel S, Siddharthan A, Tidhar D. An annotation scheme for citation function. In: Alexandersson J, Knott A, editor. Proceedings the $7^{\text {th }}$ SIG dial Workshop on Discourse and Dialogue. Stroudsburg, PA: Association for Computational Linguistics (ACM); 2006. p. 80-7.

27. Harwood N. An interview-based study of the functions of citations in academic writing across two disciplines. J Pragmat 2009;41:497-518.

28. Peroni S, Shotton D. FaBiO and CiTO: Ontologies for describing bibliographic resources and citations. Web Seman 2012;17:33-43.
29. Baker DJ. A jester's promenade: Citation to wikipedia in law reviews, 2002-2008. I/S: J Law Pol Inf Soc 2012;7:361-403.

30. Head A, Eisenberg M. How today's college students use wikipedia for course-related research. First Monday 2010;15. Available from: http://www.dx.doi.org/10.5210\%2Ffm.v15i3.2830. [Last accessed on 2013 Jan 05].

31. West K, Williamson J. Wikipedia: Friend or foe. Ref Serv Rev 2009;37:2260-710.

32. Asadi S, Ghafghazi S, Jamali HR. Motivating and discouraging factors forwikipedians: The case study of Persian wikipedia. Libr Rev 2013;62:237-52.

33. Emigh W, Herring S. Collaborative authoring on the web: A genre analysis of online encyclopedias. Proceedings of the $38^{\text {th }}$ Hawail International Conference on System Sciences (HICSS-38). Los Alamitos, CA: IEEE Press; 2005.

34. Rector LH. Comparison of wikipedia and other encyclopaedias for accuracy, breadth, and depth in historical articles. Ref Serv Rev 2008;36:7-22.

35. Stoddard MM. Judicial citation to wikipedia in published federal court opinions. Available from: http://www.ils.unc.edu/ MSpapers/3526.pdf. [Last accessed on 2012 Jul 24].

How to cite this article: Tohidinasab F, Jamali HR. Why and where Wikipedia is cited in journal articles?. J Sci Res 2013;2:231-8.

Source of Support: Nil, Conflict of Interest: None declared 